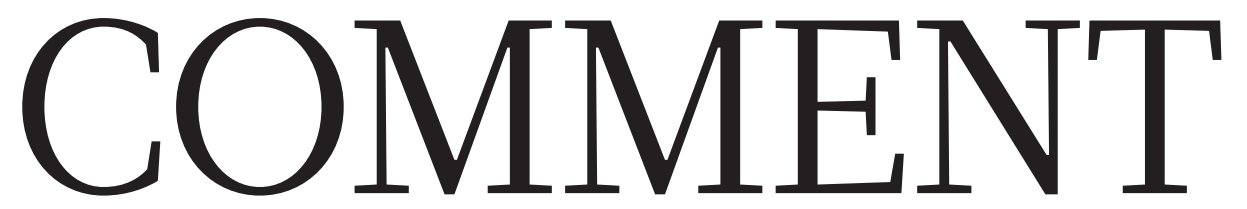

Bias Why do racial stereotypes persist in sport? p.474
PoLITICS How Hindu

nationalists have co-opted the trappings of science $\mathbf{p . 4 7 6}$
ENVIRONMENT A call to safeguard biodiversity in regions of armed conflict $\mathbf{p . 4 7 8}$
PUBLIC hEALTH Citizen science is helping to map snakebite risk $\mathbf{p . 4 7 8}$

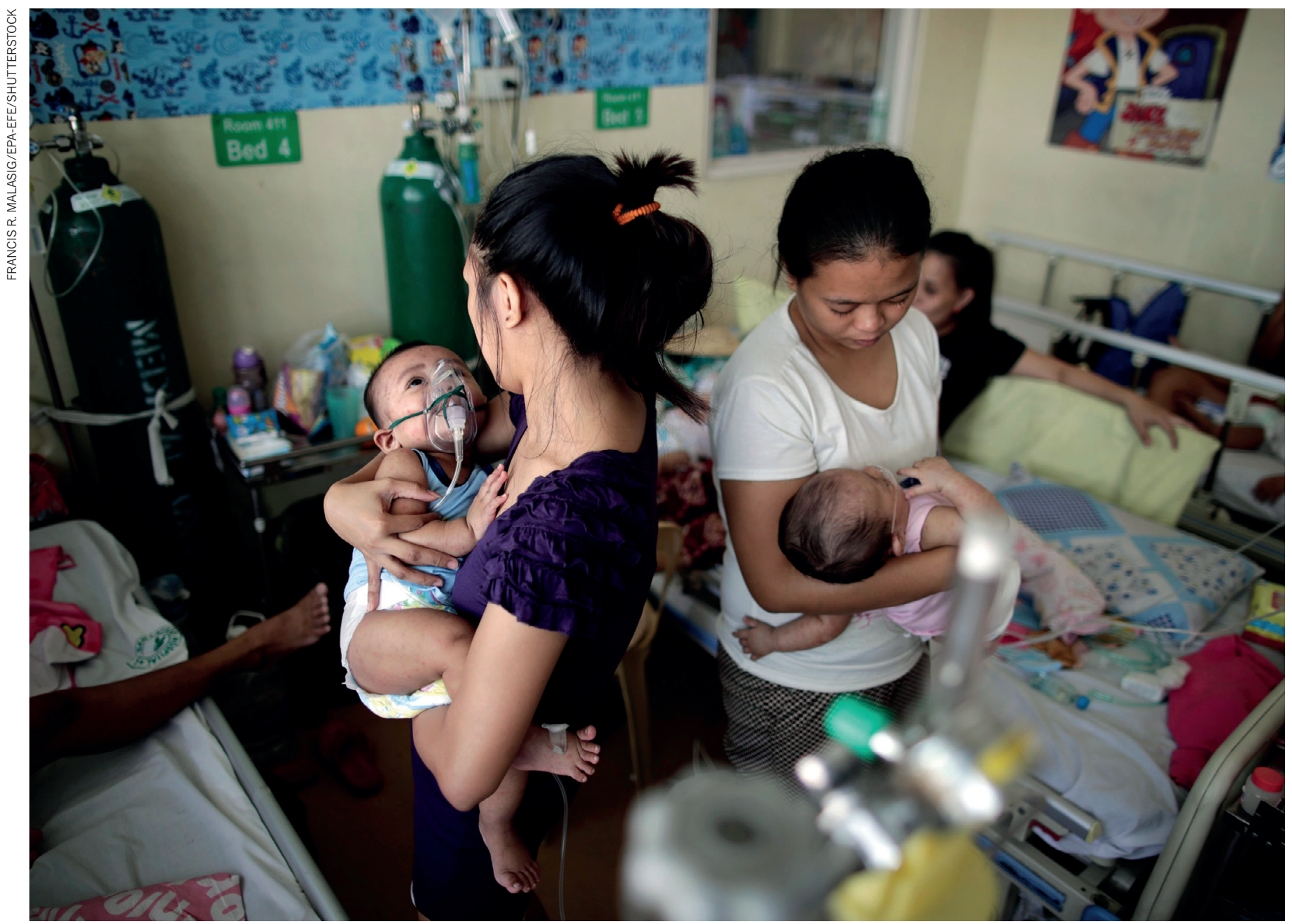

Children with measles in an overcrowded hospital ward in the Philippines, where an outbreak occurred in Manila and central Luzon in February 2019.

\title{
Mandate vaccination with care
}

Governments that are considering compulsory immunizations must avoid stoking anti-vaccine sentiment, argue Saad B. Omer, Cornelia Betsch and Julie Leask.

$\mathrm{T}$ Thousands of people worldwide have been affected by recent measles outbreaks, even though there is a safe and effective vaccine.

In the first four months of this year, the World Health Organization (WHO) reported about 226,000 measles cases - almost three times the count recorded in the same period last year (see go.nature.com/2jkq8d3).
Already, the number of cases in the United States this year has exceeded the reported tally in any year since the country halted sustained transmission of the disease in 2000. Similarly, in Europe, the 2018 figures were the highest this decade (see 'Measles on the rise').

Partly in response to these outbreaks, some governments are now considering making vaccination for measles and other diseases a legal requirement ${ }^{1}$. The state of New York signed legislation to that effect last month.

Such mandates, which began with smallpox vaccination in nineteenth-century Europe, are in place for numerous vaccines in various countries. And several studies show that requiring vaccination can $>$ 
$>$ improve rates in high-income countries (see, for example, ref. 2), although there is limited evidence of the impact of such requirements in low- or middle-income nations.

However, mandatory vaccination can worsen inequities in access to resources, because penalties for not complying can disproportionately affect disadvantaged groups. What's more, the evidence suggests that there is no simple linear relationship between the forcefulness of a policy and its impact on the rate of vaccination.

It is crucial that policies don't inadvertently entrench inequity or fuel anti-vaccine activism. As specialists in vaccination policy and programmes, we lay out here what's known, to help governments consider whether a mandate is the right fit for their situation. We also discuss what other changes should be made before introducing requirements (see 'Best practice'). And we distil how mandates should be designed to ensure effectiveness.

\section{WHICH MANDATES WORK?}

There has long been substantial variability in how governments and jurisdictions mandate vaccination - specifically, in what is actually required of people; the penalties imposed if requirements are not met; and the age groups and populations that are covered.

In the United States, for instance, proof of immunization or exemption documentation is required before children can go to school. All 50 states and Washington DC allow exemptions for medical reasons, and 45 states allow philosophical or religious exemptions. In Australia, certain vaccines are a requirement for entry into preschool or childcare in some states, but not in others. In Uganda, parents who fail to vaccinate their children can be jailed for six months.

Studies conducted largely in the United States and Europe suggest that making vaccination a requirement for enrolment in childcare and school can help to increase rates (see, for example, ref. 2). For instance, a review of studies conducted mostly in the United States found that the need to provide documentation to access childcare or to attend school and college is associated with a median improvement of 18 percentage points in the rate of vaccination for diseases such as measles, hepatitis B and whooping cough (see go.nature.com/3tzrujo).

When it comes to obtaining an exemption, having complex administrative procedures in place (such as those involving counselling with a physician) reduces the number of parents who refuse to have their children vaccinated. It also lowers the number of people who are affected by vaccine-preventable diseases $^{2}$. In a 2012 study, non-medical exemption rates were more than twice as

high in US states that had relatively easy exemption procedures, compared with states that had more complex ones ${ }^{3}$.

Given such evidence, governments have sometimes removed non-medical exemptions altogether. In the past four years, the states of Maine, New York and California joined West Virginia and Mississippi in eliminating non-medical exemptions for all or some vaccines. And in response to a media and public campaign,

\section{"There is no simple linear relationship between the forcefulness of a policy and its impact on the rate of vaccination."}

Australia implemented legislation in 2016 that prevents parents from obtaining non-medical exemptions.

Increases in vaccination rates have been associated with financial penalties. These take the form of either the withdrawal of family assistance payments (currently as much as Aus $\$ 26,000$ (US $\$ 18,200$ ) a year in Australia, by our calculations) or fines for parents who refuse to vaccinate their children. In a study evaluating mandatory vaccination in Europe, measles vaccine coverage was $0.8 \%$ higher and whoopingcough vaccine coverage was $1.1 \%$ higher for every $€ 500$ (US\$560) increase in the penalty ${ }^{4}$.

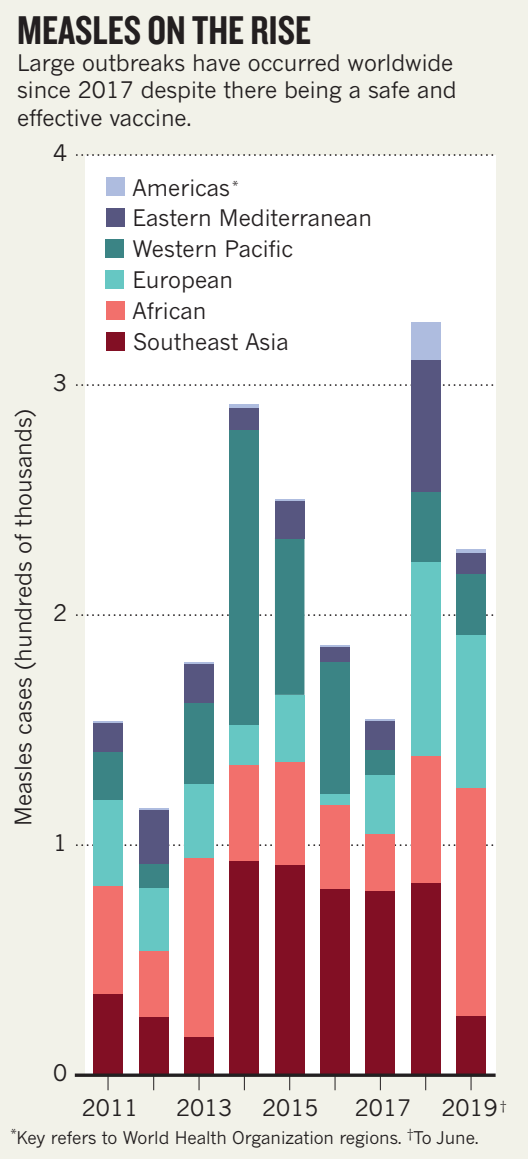

Vaccination requirements (tied to school and childcare access, or to monetary penalties) fare well in comparisons with other large-scale interventions, such as vaccination drives at schools, or communication campaigns involving pamphlets, billboards, television advertisements and so on. A 2017 review of interventions to increase vaccination found that in high-income countries, requirements to vaccinate are more likely to affect rates than are attempts to change how people think and feel about vaccination ${ }^{5}$.

\section{EXEMPTIONS AND PENALTIES}

So, in many cases, requirements to vaccinate do seem to improve vaccination rates. But do rigid, punitive policies work better than flexible ones? In our view, not necessarily. In fact, the limited data that are available suggest that a middle-of-the-road approach might be more effective. These data come mainly from California, Washington state (which eliminated personal-belief exemptions to measles, mumps and rubella (MMR) vaccination this year) and Australia.

In 2015, California became the third US state to eliminate all non-medical exemptions, and the first state to do so in more than three decades. This change in the law was preceded by a 2014 administrative initiative to reduce the misuse of a school admission process involving 'conditional entrants' - children who have started the required vaccination schedule but haven't completed it ${ }^{6}$. (Since 1979, children in California have been allowed to attend school as conditional entrants - but before 2014, only some schools followed up with parents, and some children were never fully vaccinated $^{6}$.)

The proportion of children of kindergarten age who are not up to date on their vaccinations has decreased in California, from $9.8 \%$ in 2013 to $4.9 \%$ in 2017 (ref. 7). However, this change seems to be mainly associated with the administrative crackdown on conditional entrants. Following the elimination of non-medical exemptions, many parents with strong objections to vaccination simply acquired medical exemptions instead, educated their children at home, enrolled them in independent study programmes that do not require classroom-based instruction, or found other loopholes ${ }^{6}$.

In Australia, following policy changes in 1999 , parents had to get their child vaccinated to get assistance payments. And they could obtain non-medical exemptions only after they had discussed the issue with a health-care provider. According to surveys, these policies helped to improve vaccination coverage from an estimated $80 \%$ to more than $90 \%$ in three years ${ }^{8}$.

Then, in 2016, Australia implemented a 'No Jab No Pay' policy, which removed non-medical exemptions and applied the 


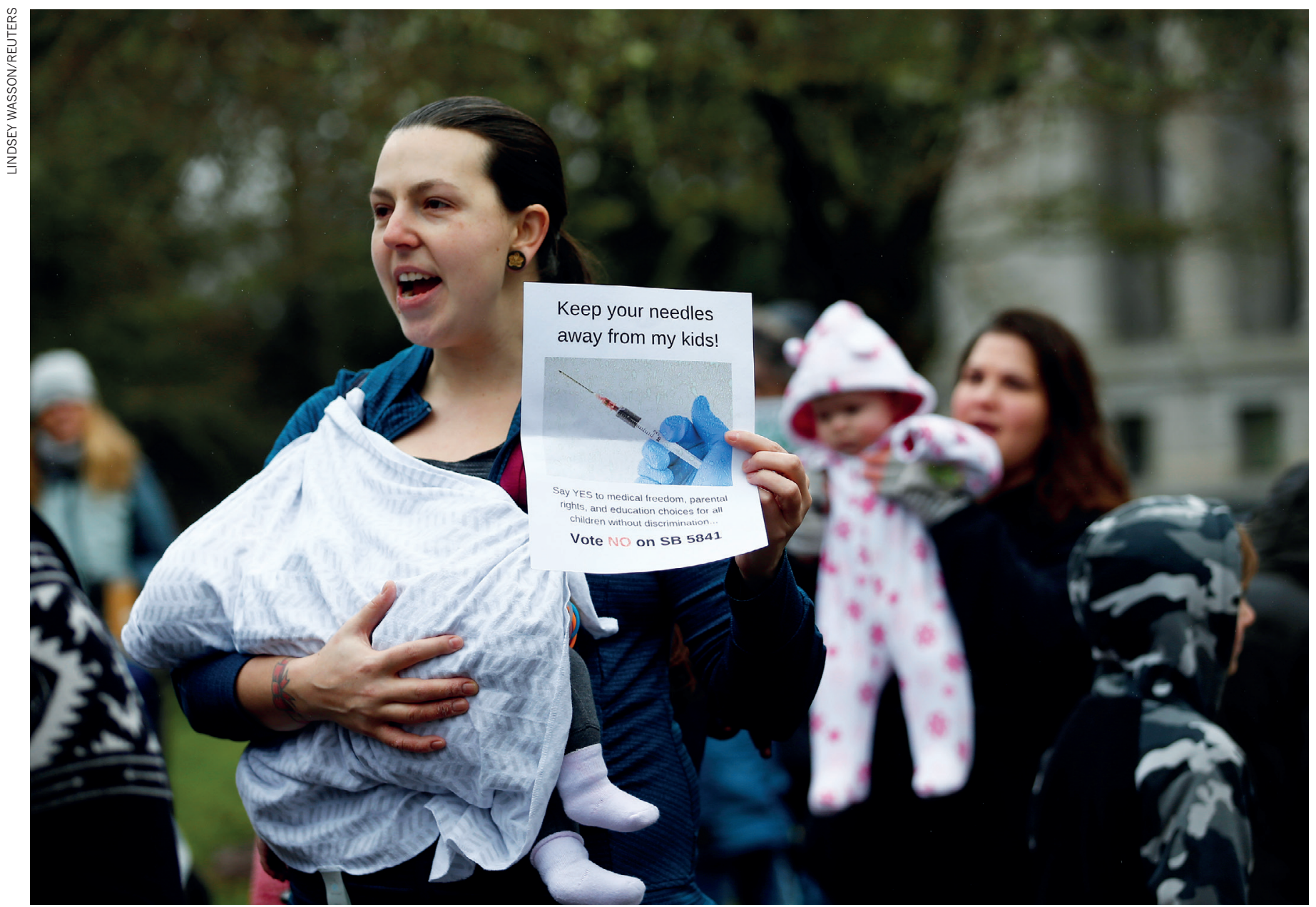

Parents on a march protesting against mandatory vaccinations in Washington state earlier this year.

loss of payments more frequently. Overall immunization rates for five-year-olds have since increased nationally, from $92.6 \%$ in 2015 to $94.8 \%$ by March 2019 (see go.nature.com/2xmgtun). But this smaller improvement comes after the roll-out of several concurrent strategies designed to improve coverage - from schemes to remind parents to get their child vaccinated, to campaigns to improve public awareness. So the impact of the 'No Jab No Pay' policy alone is unclear.

In 2017, one of us (J.L.) was involved in a study that interviewed 31 parents in Australia who were refusing vaccination for their child ${ }^{9}$. Of this group, 17 indicated that they planned to get more involved in protest action if additional such measures were implemented, because they felt that the government was coercing them. Interestingly, in an experimental study ${ }^{10}$, more people with a negative attitude towards vaccination chose to accept a hypothetical second vaccine when they had previously been told that they could choose to be vaccinated with a first vaccine. When these individuals were told that they had to be vaccinated with the first vaccine, $39 \%$ less people elected to receive the optional one $e^{10}$.

In short, various findings suggest that the most effective approach when it comes to mandating vaccination could be to allow non-medical exemptions, but to make them hard to obtain. Removing the choice of opting out entirely might simply induce parents to seek loopholes, and, worse, fuel negative attitudes towards vaccination.

\section{SMART AND ETHICAL}

If vaccination rates are low in a particular region or community, a government's first step must be to find out why. Guidance from the WHO Regional Office for Europe, for example, lays out steps for targeting specific communities, such as by working with community leaders, healthcare workers and service users to establish whether people are struggling to get to their local clinics or avoiding health-care providers for some other reason ${ }^{11}$. (J. L. was a reviewer of this guide, and all three of us have received funds from the $\mathrm{WHO}$, which, as a UN agency, has no financial competing interest regarding this article.)

Mandates are often inspired by the perception among politicians and the public that vaccine refusal by parents is the biggest problem. But poverty, social exclusion and difficulties over access also depress rates, and, in many settings, more so than refusal. In Germany, for example, barriers to access probably explain why children of migrant parents have a $10 \%$ lower immunization rate for booster doses (such as for tetanus or human papillomavirus) than do children who were born there ${ }^{12}$.

A requirement to vaccinate when the vaccine or primary-care service is difficult or impossible for many people to reach is not justifiable or fair ${ }^{13}$. Thus, before even considering mandates, governments must ensure that people from all sectors of society can get vaccines easily and safely. This means making primary-care services flexible, welcoming and easy to reach, and ensuring a stable supply of vaccines.

If governments then decide that mandates are appropriate, they should take the following five steps.

Use multiple interventions. Ideally, requirements to vaccinate should be part of a suite of interventions. These could include: robust methods for recording immunization, such as in a registry; textmessage or e-mail reminders to parents before a child's vaccines are due; and a process to monitor and give feedback on how primary-care providers perform on vaccination rates $^{5}$ (see also go.nature. 


\section{BEST PRACTICE}

Before even considering mandatory vaccination, governments must first ensure easy access to vaccines. (Examples in white boxes are not exhaustive.)

\begin{tabular}{|c|c|c|}
\hline \multicolumn{2}{|c|}{ Essential } & $\begin{array}{l}\text { If mandates are politically } \\
\text { considered appropriate }\end{array}$ \\
\hline $\begin{array}{c}\text { STEP } 1 \\
\text { Ensure everyone can } \\
\text { access vaccines }\end{array}$ & $\begin{array}{c}\text { STEP } 2 \\
\text { Use multiple interventions } \\
\text { to improve uptake }\end{array}$ & $\begin{array}{l}\text { STEP } 3 \\
\text { Create smart and } \\
\text { ethical mandates }\end{array}$ \\
\hline $\begin{array}{c}\text { Ensure stable supply } \\
\text { of vaccines }\end{array}$ & $\begin{array}{l}\text { Diagnose reasons for } \\
\text { under-vaccination }\end{array}$ & $\begin{array}{c}\text { Ensure procedures } \\
\text { are fair }\end{array}$ \\
\hline $\begin{array}{l}\text { Make clinics welcoming, } \\
\text { safe and easy to get to }\end{array}$ & $\begin{array}{l}\text { Use immunization } \\
\text { registry and reminders }\end{array}$ & $\begin{array}{l}\text { Make penalties } \\
\text { appropriate }\end{array}$ \\
\hline \multirow[t]{2}{*}{ Monitor safety } & $\begin{array}{l}\text { Monitor performance of } \\
\text { providers and give feedback }\end{array}$ & $\begin{array}{l}\text { Compensate for } \\
\text { side effects }\end{array}$ \\
\hline & $\begin{array}{l}\text { Provide vaccinations in } \\
\text { communities }\end{array}$ & $\begin{array}{l}\text { Avoid implementing } \\
\text { selective mandates }\end{array}$ \\
\hline
\end{tabular}

com/3puzrga). All of these interventions should be in place whether or not mandates are implemented (see 'Best practice').

Ensure just procedures. Limited restrictions on personal autonomy are more likely to be workable in democracies. In these, societies are more able to express their collective will than in dictatorships, where such restrictions can be abused. Indeed, it is crucial that the process of developing mandates is itself democratic. Deliberative methods can ask what an informed citizenry would find an acceptable policy response and why. A good model is the community juries used for more than two decades, mostly in the United States, Australia and Canada, to address policy issues in other areas of health care, such as for cancer screening. In these, panels of citizens hear evidence, then debate the issue and give their verdicts ${ }^{14}$.

Make penalties proportionate. In our view, incarceration is never justified for enforcing vaccination. Temporary quarantine or the use of child protection laws might be an appropriate action when the risk of a vaccine-preventable disease is very high (such as in a newborn whose mother tests positive for hepatitis B $)^{15}$. Even with penalties such as fines, withheld benefits or blocked entry to childcare or schools, care must be taken to ensure that they do not exacerbate social or health inequities.

Monitor safety and compensate for side effects. In the exceedingly rare instances in which required vaccines cause harm, those affected should be adequately compensated. (For instance, around 2.6 cases of the rare bleeding disorder thrombocytopenic purpura arise for every 100,000 doses of MMR vaccine that are given ${ }^{16}$.)

Proactive surveillance systems that monitor side effects should be paired with a timely programme for compensation that minimizes administrative and legal burdens for those injured ${ }^{17}$. In the United States, people seeking compensation following vaccination have to demonstrate only that they (or their child) had an adverse event known to be associated with the vaccine. By contrast, people in Australia have to pursue compensation through the courts - a time-consuming and expensive process.

Such programmes can be financially sustainable. In the United States, vaccine manufacturers are taxed on vaccines sold in the country to finance this (currently, 75 cents per antigen). Other financial models have been proposed, including for low and middle-income countries ${ }^{18}$.

Avoid selective mandates. Governments should avoid making specific vaccines mandatory. In France in the 1960 s, there was a policy shift. Older vaccines such as those for smallpox, diphtheria, tetanus, tuberculosis and polio remained mandatory; newer

\section{"Experimental evidence shows that making one vaccine mandatory might reduce people's uptake of others."} ones for diseases such as measles were only 'recommended'19. For many years, there has been a difference in uptake of up to $20 \%$ between the two classes. Vaccines that were 'only' recommended were perceived as non-essential by French parents. (In 2018, the recommended vaccines became mandatory ${ }^{20}$.) And experimental evidence shows that making one vaccine mandatory might reduce people's uptake of others ${ }^{10}$. In our view, Germany, which is currently considering a mandate for just measles, should rethink.

In summary, making vaccination a legal requirement can be a powerful and effective tool if implemented with care and with regard to the context. Crucially, evidence for the effectiveness of mandates is largely limited to high-income countries.

Overly strict mandates can result in parents finding ways to avoid the vaccine requirements, and selective mandates might damage the broader vaccination programme. Most importantly, vaccine policy - like other types of effective public policy - must be based on evidence, and not driven by political and ideological considerations.

Saad B. Omer is the director of the Yale Institute for Global Health; professor of medicine (infectious diseases) at Yale School of Medicine; and professor of epidemiology of microbial diseases at Yale School of Public Health, New Haven, Connecticut, USA. Cornelia Betsch is professor of health communication at the University of Erfurt, Psychology and Infectious Diseases Lab, Erfurt, Germany. Julie Leask is professor in the Susan Wakil School of Nursing and Midwifery at the University of Sydney, Faculty of Medicine and Health, Camperdown, New South Wales, Australia. e-mail: julie.leask@sydney.edu.au

1. MacDonald, N. E. et al. Vaccine 36, 5811-5818 (2018).

2. Omer, S. B. et al. J. Am. Med. Assoc. 296 1757-1763 (2006).

3. Omer, S. B., Richards, J. L., Ward, M. \& Bednarczyk, R. A. N. Engl. J. Med. 367, 1170-1171 (2012)

4. Vaz, O. M. et al. Pediatrics (in the press).

5. Brewer, N. T., Chapman, G. B., Rothman, A. J., Leask, J. \& Kempe, A. Psychol. Sci. Public Interest 18, 149-207 (2017).

6. Delamater P. L. et al. Pediatrics 143, e20183301 (2019).

7. Pingali, S. C. et al. J. Am. Med. Assoc. 322, 49-56 (2019).

8. Bond, L., Davie, G., Carlin, J. B., Lester, R. \& Nolan, T. Aust. N. Z. J. Public Health 26, 58-64 (2002).

9. Helps, C., Leask, J. \& Barclay, L. J. Pub. Health Policy 39, 156-169 (2018).

10.Betsch, C. \& Böhm, R. Eur. J. Public Health 26, 378-381 (2016).

11. World Health Organization Regional Office for Europe. The Guide to Tailoring Immunization Programmes (TIP) (WHO, 2013).

12.Poethko-Müller, C., Kuhnert, R., Gillesberg Lassen, S. \& Siedler, A. [in German] Bundesgesundheitsblatt Gesundheitsforschung Gesundheitsschutz 62, 410-421 (2019).

13. Boyce, T. et al. Eurosurveillance 24, 1800204 (2019).

14.Degeling, C., Rychetnik, L., Street, J., Thomas, R. \& Carter, S. M. Soc. Sci. Med. 179, 166-171 (2017).

15.Isaacs, D., Kilham, H., Leask, J. \& Tobin, B. Vaccine 27, 615-618 (2009)

16.Mantadakis, E., Farmaki, E. \& Buchanan, G. R. J. Pediatr. 156, 623-628 (2010).

17. Attwell, K., Drislane, S. \& Leask, J. Vaccine 37 2843-2848 (2019)

18. Halabi, S. \& Omer, S. B. J. Am. Med. Assoc. 317 471-472 (2017).

19.Attwell, K. et al. Vaccine 36, 7377-7384 (2018).

20.Lévy-Bruhl D. et al. Eurosurveillance 24, 1900301 (2019). 